\title{
LA TUTELA DEL INCAPAZ EJERCIDA POR LA ENTIDAD PÚBLICA
}

Estudio del artículo 239.3 del Código Civil

Antonio Legerén Molina

Editorial Universitaria Ramón Areces

(c) Fundación Aequitas, Editorial Centro de Estudios Ramón Areces.

ISBN-13-978-84-9961-108-2

Madrid 2012

255 páginas.

Ignacio Serrano García

Catedrático de Derecho civil

Vicepresidente de la Asociación Española de Fundaciones Tutelares

Es lástima que se haya deslizado un error en la portada del libro, porque el número del artículo que se estudia en el trabajo es el 239.3 del Cc, mientras que el que aparece es el 293.3.

Se trata de la obra que ha ganado el $X$ Premio Aequitas de "Investigación Jurídica en la Prevención, Rehabilitación, Integración Social o Promoción de las Personas con Discapacidad, Personas Mayores, Inmigrantes, Infancia, refugiados u otros grupos que carezcan de la debida protección".

El libro es resultado de una investigación llevada a cabo por un importante grupo de profesores, dirigido por el Catedrático de Derecho civil de la Universidad de Zaragoza, Dr. Carlos Martínez de Aguirre. 
Consta de cuatro partes que se refieren: $1^{\mathrm{a}}$ ) La protección jurídica ante la falta de capacidad; $2^{\mathrm{a}}$ ) Los sujetos activo y pasivo de la tutela ejercida por la entidad pública; $3^{\mathrm{a}}$ ) Los supuestos de hecho a los que es aplicable el artículo 239.3 del Código Civil; 4ª) Crítica del artículo 239.3 del Código Civil. Al final se incluye una bibliografía y un índice de resoluciones citadas.

Se contiene, al inicio, un prólogo firmado por el ilustre Notario Federico Cabello de Alba Jurado, dedicado desde hace años al estudio de los problemas de la discapacidad y a difundir los instrumentos jurídicos de inserción de las personas afectadas en la vida ordinaria.

Se parte de una idea que va extendiéndose de que la falta de capacidad no se remedia en el ámbito familiar exclusivamente, sino que se ha institucionalizado. La afirmación es interesante y conviene enfatizar esta idea. El instituto típico de protección (apoyo) de las personas con discapacidad es la tutela, que era definida por nuestros clásicos como un oficio de Derecho privado y, en consecuencia, se atribuía la tutela a algún familiar que la ejercía con la supervisión de un protutor, y ambos controlados por un Consejo de Familia. De esta tutela de familia se ha pasado a otra de autoridad, encomendándose la supervisión y vigilancia de la tutela a los Jueces y Fiscales. No obstante el papel protagonista de los Jueces y Fiscales en la tutela, la delación de la misma se hacía a favor de familiares. La importante reforma del Code civil francés de 2007 (entrada en vigor el $1^{\circ}$ de enero de 2009) sobre les majeurs protégés señala que la tutela de menores est une charge publique. Elle est un devoir des familles et de la collectivité publique (art. 394) y la de mayores est un devoir des familles et de la collectivité publique.

Ya no se trata sólo de un cargo de Derecho privado, sino de una institución que concierne a las familias, pero también a los poderes públicos.

En el Derecho español esta tendencia se inicia con la reforma del artículo 172 del Código civil operada por la Ley Orgánica de Protección Jurídica del Menor de 1996, luego modificada por otra Ley de 2007, cuando inicialmente se encuadraba dentro de la adopción.

En 2003, con la Ley de Protección Patrimonial de las Personas con Discapacidad (sigue un larguísimo título), se introduce un tercer párrafo en el artículo 239, de redacción imposible de entender, que yo he tratado de explicar, y que el autor recoge en las pp. 66 (nota 87) y 69. Pues efectivamente únicamente se entiende alterando el orden de los párrafos en el siguiente sentido: "La entidad pública a la que, en el respectivo territorio, esté encomendada la tutela de los incapaces asumirá por ministerio de la ley la tutela del incapaz cuando ninguna de las personas recogidas en el artículo 234 sea nombrado tutor o cuando éste se encuentre en situación de 
desamparo". Es la única manera de entender la norma que, con la redacción publicada en el BOE no se entiende.

El autor explica acertadamente que la figura surge cuando no hay familiares o cuando hay desamparo. Anteriormente, si no había familiares se encomendaba la tutela al Director del Centro donde se encontrara la persona, desconociendo la existencia de incapaces no institucionalizados, pero que merecen una atención tutelar, al margen de la residencial que puede no ser precisa. Plantea la cuestión de si estamos ante una tutela administrativa o de una ordinaria, y de si es preciso en el segundo de los casos (desamparo) una declaración judicial de modificación de la capacidad o surge automáticamente cuando el desamparo se acredita. Se apuntan otros interesantes problemas como el de si estamos ante dos figuras diferentes: cuando no hay familiares, tutela ordinaria, cuando desamparo, tutela administrativa, similar a la del 172 para los menores desamparados. Habría otra posibilidad y es la de que en ambos supuestos estamos ante una tutela (entendida, en sentido amplio, como medida protectora) distinta de la ordinaria, concebida como función transitoria de protección.

En la página 87 se concluye la opinión del autor acerca de la tutela del 239.3, cuando dice: “...dada la deficiente técnica legislativa del precepto -que no delimitó de manera completa el contenido de la norma-, el término incapaz en un caso sólo puede referirse a las personas con capacidad de obrar modificada -primer supuesto de hecho: “cuando ninguna de las personas recogidas en el artículo 234 Cc sea nombrado tutor"-, mientras que, en el otro, admite dos posibilidades de interpretación: referirlo a las personas con capacidad de obrar modificada y también a los incapaces de hecho -segundo de los supuestos de hecho: "cuando éste se encuentre en situación de desamparo"-. Que un mismo término pueda tener significados distintos evidencia la deficiente técnica legislativa, lo que no resulta especialmente novedoso por cuanto el propio Código civil no usa en todas las ocasiones el término "incapaz" con rigor técnico y en un mismo sentido: a veces remite a persona cuya capacidad de obrar haya sido judicialmente modificada: a veces a un incapaz de hecho. La falta de técnica legislativa se aprecia también en la inexistencia de desarrollo normativo del artículo 239.3 del Código civil: el texto del precepto está "sin acabar" y deja sin resolver algunas cuestiones esenciales para su aplicación y desarrollo."

No obstante ser un tanto ambiguo, el autor parece inclinarse (en el lugar ya citado y más ampliamente en p. 194 "Elementos del desamparo: la situación de desprotección y el incumplimiento de deberes") por la solución de que la tutela de los mayores desamparados puede referirse tanto a los que tienen la capacidad de obrar modificada, como a los incapaces de 
hecho no incapacitados. La cuestión no es fácil de resolver, de ahí las dudas que el autor manifiesta, porque frente a la autonomía de los mayores, existe la obligación constitucional plasmada en el artículo 49 de la CE.

He sostenido ${ }^{1}$ que no existen mayores desamparados no incapacitados, porque no existe obligación para nadie de amparar a un mayor capaz. Partiendo de la premisa que enfatizó Federico de Castro, acerca del estado civil, habría que distinguir: estado civil de minoridad y estado civil de mayor; dentro de las dos categoría se podría seguir distinguiendo: estado civil de capacidad y estado civil de incapacidad, lo que puede aplicarse tanto a los menores de 18 años como a los que ya han cumplido esa edad. El estado civil de capacidad no es una categoría única porque puede referirse tanto a menores como a mayores con capacidades distintas. Los menores no incapacitados y que están, por ello en el estado civil de minoridad, tienen la capacidad correspondiente a su situación (son capaces para testar, para casarse con dispensa, en su caso, pueden ser emancipados...). Y, por último habría que decir que los que se encuentran en el estado civil de incapacidad sólo lo están cuando ha habido una sentencia judicial que modifica su capacidad de obrar. Los mayores de 18 años que no tienen modificada su capacidad, o con la terminología anterior, que no han sido judicialmente incapacitados, son personas que se encuentran en el estado civil de mayoridad y, por ello, tienen autonomía y no hay nadie que tenga la obligación de ampararles. No desconozco que pueden encontrarse bajo guarda de hecho. Pero el guardador es cargo voluntario (referido, según dispone el $303 \mathrm{Cc}$ a menores y presuntos incapaces), a diferencia del tutor que tiene un deber.

No me parece correcto, por tanto, que una persona que tiene el estado civil de mayor, pueda ser tutelado, porque la tutela de mayores sólo cabe cuando el mayor de 18 (no en el estado civil de mayor de edad) está judicialmente con la capacidad de obrar modificada. No obstante la opinión que sostengo, soy consciente de la letra de la norma $(239.3 \mathrm{Cc})$, que atribuye una tutela ministerio legis a los mayores que estén en desamparo. Una tutela a la fuerza para alguien que está en el estado civil de mayor de edad, no me parece que pueda existir. Sólo podría entenderse creyendo que esa llamada tutela no es la del capítulo $2^{\circ}$ del título $\mathrm{X}$ del Código civil. Sería una tuición que podría ofrecerse, nunca imponerse, a los desamparados. En consecuencia de esta oferta, la persona afectada puede aceptarla o rechazarla. Únicamente puede imponerse una tuición (o un apoyo; aunque el término apoyo es contradictorio con la imposición) cuando previamente se le ha modificado la capacidad de obrar. Me parece que otra solución podría caer bajo la abominada legislación de vagos y maleantes, felizmente desaparecida, sobre todo por lo

\footnotetext{
${ }^{1}$ Ignacio SERRANO GARCÍA, Protección patrimonial de las personas con discapacidad. Tratamiento
} sistematico de la Ley 41/2003, Madrid 2008, pp. 513 a 546. 
que a la vagancia respecta, porque no se puede imponer a nadie que sea diligente. La ausencia de diligencia puede tener otras consecuencias, como la de ser causa para no poder obtener alimentos, pero nada más. La tutela, esencialmente es representación y, por ello, actuación en nombre y por cuenta de otro. No es posible sostener, hoy día, que alguien pueda irrogarse la facultad de actuar por otro (en su nombre) si no ha existido antes, una declaración judicial eliminando la facultad de decidir autónomamente ${ }^{2}$. A estas consideraciones hay que añadir que el desamparo de los mayores si bien está definido en el $239.3 \mathrm{Cc}$, no se señala quién lo determina. Ya he dicho que, entiendo, que no hay mayores desamparados no incapacitados, pero como quiera que el Código los menciona, por lo menos debería señalar la autoridad con facultad para declarar la situación de desamparo: judicial o administrativa. Como bien señala el autor hay un vacío importante en esta norma que podría salvarse con la interpretación citada en la obra, de SANTOS URBANEJA cuando señala que si, al iniciarse un procedimiento de modificación de la capacidad se advierte, ya inicialmente un desamparo, se podrían adoptar inmediatamente como medidas cautelares, el sometimiento a una tutela administrativa provisional ejercida por la entidad pública. Esta opinión me parece correcta porque en una medida que, se quiera o no, restringe la libertad de las personas, interviene la autoridad judicial, que es la única que puede adoptar este tipo de decisión afectante a la libertad personal. Hay que manifestar también que la protección, o el apoyo (más correcto hoy, después de la Convención de la ONU) puede ser muy variado: desde la obligación de someterse a un tratamiento médico (especialmente indicado para los enfermos mentales) hasta medidas de ayuda familiar que pueden perfectamente suministrar los servicios sociales tanto autonómicos como municipales. Porque el problema que, en ocasiones, es transitorio, puede remediarse con una ayuda para realizar las tareas domésticas que la persona no puede desempeñar por una enfermedad, por ejemplo ${ }^{3}$.

Y quiero dejar bien claro que no estoy eximiendo a las Administraciones públicas de la obligación que tienen de ofrecer ayudas a los que nada tienen, y más especialmente a los que, además de no tener nada, carecen o tienen disminuida la capacidad de tomar decisiones. No. Las Administraciones (estatal, autonómica o local) tienen que tejer una red de apoyos para cubrir las necesidades de quienes -en la terminología del Código en el 239.3 están “desamparados”. Pero

\footnotetext{
2 Dice el autor en

${ }^{3}$ No se puede desconocer que con excesiva frecuencia problemas sociales se intentan resolver a través del sometimiento a tutela de quien sólo necesita una ayuda, con frecuencia temporal. Hay, en este sentido, un abuso de la tutela con finalidades distintas de las que persigue el instituto. Son, sobre todo los CEAS de zona municipales, los que instan a los Fiscales a presentar demandas de incapacitación para remediar situaciones que los propios servicios sociales podrían resolver.
} 
sostengo y aseguro que esta red de apoyos es una oferta para el que lo necesite; nunca será obligatorio integrarse en ella. Para hacerla obligatoria tiene que intervenir la autoridad judicial.

Es interesante, como todo el libro por otra parte, las páginas que dedica a las fundaciones tutelares. Se estudia la figura cuando estudia el sujeto activo de la tutela ("la entidad pública"). Las fundaciones tutelares son una creación del movimiento asociativo de las personas con discapacidad intelectual (como ahora se dice; en su momento personas con deficiencia mental), muy activo en la protección de quienes padecen una discapacidad intelectual o del desarrollo, ahora inmersas en el CERMI. Estas fundaciones creadas por iniciativa privada (esencialmente por FEAPS) han tenido un enorme éxito, aunque padecen ahora la crisis que afecta a todos los españoles, porque son fundaciones con un patrimonio muy pequeño y viven económicamente con subvenciones otorgadas por las Consejerías encargadas de los servicios sociales de las Comunidades Autónomas. En estos momentos de escasez, viven tiempos difíciles.

\footnotetext{
${ }^{4}$ A iniciativa de la Asociación Española de Fundaciones Tutelares han elaborado el documento: Josep Tresserras (SOM, Fundació Catalana Tutelar Aspanias), Marta Sunyer (Futumad, Fundación tutelar de Madrid), Pedro Ma Fernández Robles (Futudis, Fundación tutelar Castellano Leonesa de Personas con discapacidad intelectual o del desarrollo), Mikel de Barrón (Futubide, Fundación tutelar Gorabide) y Arancha Pinar (Asociación Española de Fundaciones Tutelares), Modelo de tutela, Madrid 2012.

${ }^{5}$ Existen muchas otras Fundaciones Tutelares. A las que me refiero en el texto son a aquéllas que se ocupan de las personas con discapacidad intelectual o del desarrollo. No se olvide, sin embargo que otras fundaciones tutelares tienen encomendada la tutela de los enfermos mentales, y otras, finalmente tienen la encomienda de atender y apoyar a los mayores (de los mayores, a los ancianos) incapacitados. Estos tres tipos son los más comunes, existiendo otras Fundaciones y, en ocasiones, Asociaciones, que también tutelan, aunque sin la especialización de las mencionadas.

${ }^{6}$ Hablo de que ejercen la tutela con economía de medios, y tengo que concretar que, por lo menos en el caso de la Fundación para personas con discapacidad intelectual de Castilla y León, la aportación económica de la Junta de CyL sólo cubre el 30 \% (aproximadamente) del coste de tutelar de esta población, teniendo que cubrir el resto del gasto con las retribuciones de la tutela. Desgraciadamente para los tutelados, hay una corriente fuerte de opinión que cree que estas tutelas tienen que ejercerse de forma gratuita para los tutelados. Si esta opinión se generalizara y se denegaran las retribuciones, las subvenciones de la Junta, tendrían que aumentar considerablemente.

${ }^{7}$ Lo cual conduce a situaciones abusivas porque el órgano de gobierno de la Comunidad autónoma es quien crea la fundación, la dota y la propia C.A. ostenta el protectorado. Se trata, una ves más, de la huida del Derecho Administrativo. Esto es lo que ocurre con la Fundación de Acción Social y Tutela (FAST) creada por la Junta de Castilla y León, o las Fundación Tutelar de La Rioja y otras.
} 